\title{
Conceitos de ecologia aplicada: bases da biodiversidade
}

Embora todos os sistemas sejam cadeias com elos de força variável, também acontece de alguns sistemas naturais se desintegrarem com maior facilidade que outros, com uma rápida e irreversível modificação em seu todo. A atividade humana agora afeta todas as regiões da Terra (nenhum refúgio, nem mesmo no mais profundo abismo oceânico, existe mais em estado primitivo natural), assim mais e mais espécies estão suscetíveis à extinção. Muitas desaparecerão antes mesmo de tornarem-se conhecidas pela ciência. Algumas carregarão para sua tumba recursos energéticos valiosos e insubstituíveis.

Palavras-chave: Biodiversidade; Ecologia; Atividade humana.

\section{Concepts of applied ecology: bases of biodiversity}

Although all systems are chains with variable strength links, it is also the case that some natural systems disintegrate more easily than others, with rapid and irreversible modification as a whole. Human activity now affects all regions of the Earth (no refuge, not even in the deepest ocean abyss, there is more in a natural primitive state), so more and more species are susceptible to extinction. Many will disappear before they even become known to science. Some will carry valuable and irreplaceable energy resources to their tombs.

Keywords: Biodiversity; Ecology; Human activity

Topic: Notas Científicas

Reviewed anonymously in the process of blind peer
Received: $14 / 02 / 2020$

Approved: 21/05/2019
Cleber Vinicius Vitorio da Silva (iD

Universidade Federal Rural do Rio de Janeiro, Brasil

http://lattes.cnpq.br/4275890458575782

http://orcid.org/0000-0001-8337-9615

clebervitorio88@gmail.com

Elenice Rachid da Silva Lenz (id

Universidade do Estado do Rio de Janeiro, Brasil

http://lattes.cnpq.br/4557023865361858

http://orcid.org/0000-0002-1440-4271

erachid@pet.coppe.ufri.br

\section{Evandro Lima (DD}

Universidade Federal Rural do Rio de Janeiro, Brasil http://lattes.cnpq.br/7057930279111732

http://orcid.org/0000-0003-4213-9652

evandrolimaabpg@uol.com.br
Gustavo Aveiro Lins (id)

Universidade Federal Rural do Rio de Janeiro, Brasil

http://lattes.cnpq.br/5173989372426437

http://orcid.org/0000-0002-0244-6925

gustavoaveiro@gmail.com

Josimar Ribeiro de Almeida (iD

Universidade do Estado do Rio de Janeiro, Brasil

http://lattes.cnpq.br/3215586187698472

http://orcid.org/0000-0001-5993-0665

almeida@poli.ufri.br

\section{Lais Alencar de Aguiar iD}

Comissão Nacional de Energia Nuclear, Brasil

http://lattes.cnpq.br/5785500333245448

http://orcid.org/0000-0002-1551-4085

aguiar.lais@gmail.com
Pauli Adriano de Almada Garcia (iD) Universidade Federal Fluminense, Brasi http://lattes.cnpq.br/3866888351512590 http://orcid.org/0000-0002-3934-4332 pauliadriano@gmail.com

Raphael do Couto Pereira (ic) Escola Naval, Brasil http://lattes.cnpq.br/2232319377341816 http://orcid.org/0000-0002-3934-4332 rcoutopereira1@gmail.com

Vanessa da Silva Garcia (10)

Universidade Federal Fluminense, Brasil http://lattes.cnpq.br/2206038698250045 http://orcid.org/0000-0002-7841-8410

vanessa.sgarcia@gmail.com

\section{Referencing this:}

SILVA, C. V. V.; LENZ, E. R. S.; LIMA, E.; LINS, G. A.; ALMEIDA, J. R.; AGUIAR, L. A.; GARCIA, P. A. A.; PEREIRA, R. C. C.; GARCIA, V. S.. Conceitos de ecologia aplicada: bases da biodiversidade. Agriculturae, v.2, n.1, p.1-3, 2020. DOI: http://doi.org/10.6008/CBPC2674-

DOI: 10.6008/CBPC2674-645X.2020.001.0001 645X.2020.001.0001 


\section{INTRODUÇÃO}

Todos os sistemas naturais possuem um elo mais suscetível a mudanças na cadeia de causa e efeito: um ponto em que o mínimo acréscimo de tensão traz consigo alterações no conjunto do sistema. Uma intervenção humana deliberada ocorrendo naqueles pontos vulneráveis ou de alavanca do meio físico, fará com que um mínimo de esforço produza o máximo de resultados. Em tese, é muito mais fácil chegar-se a alteração na biosfera por mudança na vegetação, como o desmatamento, do que alterando os outros fatores interdependentes do solo ou do clima.

\section{RELATO}

A abordagem sistêmica é umas das maneiras de se compreender os sistemas naturais. No contexto de interferência humana no ambiente, essa abordagem pode servir como meio de previsão das mudanças, de avaliação de sensibilidade dos sistemas naturais e de determinação dos pontos de interferência e dos limiares de sistema que poderão ser modificados através de impactos ambientais. Consequentemente, neste sentido pode-se aplicar o conhecimento ecológico ao planejamento e gestão ambiental. Em países em vias de desenvolvimento como o Brasil e enfatizando o espaço geográfico do Domínio Tropical Atlântico como um dos polos mais importantes de crescimento, onde a ocupação e a modificação dos mais diversos ambientes naturais se efetuam de maneira rápida e intensiva, é praticamente desnecessário salientar a urgência que se faz do estímulo, apoio e incremento dos mais diversos estudos e pesquisas de caráter holístico das Ciências Ambientais. O consumo individual de energia, recursos e comida produzida nos altos níveis tróficos deve ser reduzido. É inconcebível que a Terra possa sustentar a depleção de recursos e energia que resultaria se todo mundo consumisse no nível agora apresentado pelos cidadãos afluentes dos países desenvolvidos. A eficiência pode ser aumentada e o consumo supérfluo reduzido sem diminuir o conforto ou o prazer da vida. A insistência num estilo de vida de alta energia amplifica a pressão que a superpopulação inflige nos recursos mundiais e na qualidade de vida do meio ambiente. Cada indivíduo humano pode reduzir seu impacto comendo num nível trófico mais baixo da cadeia alimentar, investindo em tecnologias recursoeficientes e energético-eficientes, e vivendo mais próximo do equilíbrio com o mundo físico. Embora seja inevitável que a maior parte do mundo caia sob a administração humana, os sistemas devem ser mantidos tão próximos de seu estado natural quanto possível para manter os processos do ecossistema natural intactos. Como uma regra geral, quanto menos alterarmos a natureza, mais fácil será sustentar o mundo numa condição saudável. Por exemplo, muitas áreas cobertas por florestas tropicais são inadequadas para pastagem ou agricultura porque essas atividades desmontam os processos naturais de manutenção do ecossistema e causam deterioração da terra. Essas áreas devem ser deixadas como florestas de preservação e recuperação ou como sítios para exploração sustentada de recursos da floresta. Os desertos podem ser irrigados, e eles muitas vezes tornam-se tremendamente produtivos para certos tipos de agricultura. Mas os custos de manter tais sistemas manejados podem ser extremamente altos à medida que os solos acumulam sais da água de irrigação e os aquíferos esgotam-se. A taxa de desaparecimento de certos tipos de espécies, 
particularmente sujeitas à caça, poluição e destruição de habitat, está provavelmente agora mais alta do que já esteve em toda história da Terra. A causa desta perda acelerada de espécies está diretamente ligada ao crescimento e às capacidades tecnológicas da população humana.

\section{DISCUSSÃO}

As variações em sistemas tropicais são muitas vezes comparáveis às dos ambientes temperados, havendo inclusive alta incidência de sazonalidade. Há discussão a respeito de que fatores seriam os responsáveis pelo surgimento das espécies sazonais nos trópicos, uma vez que algumas delas surgem na época seca e não na estação de chuvas. Tais padrões de ocorrência afetam diretamente a estrutura das comunidades das quais as populações fazem parte, e consequentemente, os parâmetros destas comunidades devem variar em função da dinâmica das populações envolvidas. As alterações em ambientes naturais, sejam por atividade antrópica ou por fenômenos outros de natureza biótica e abiótica, em geral levam a uma modificação da comunidade local. Em matas, distúrbios como a abertura de clareiras podem levar a uma redução do número de espécies e/ou favorecimento de uma ou mais dessas espécies. Com isso, a diversidade é reduzida. Um grande problema em Ecologia é identificar os fatores que determinam a distribuição e o número de espécies em uma comunidade.

\section{CONSIDERAÇÕES FINAIS}

A solução para esse problema pode ser obtida através dos programas de monitoramento. Na verdade, esses programas têm surgido para responder uma série de questões, entre as quais, o número de espécies existentes no mundo, o monitoramento e o manejo da biodiversidade são importantes na medida em que permitem estabelecer prioridades para preservação de espécies, detectar mudanças na diversidade biológica, permitindo o ajuste a tempo de atividades de manejo ou evitar tendências não desejadas.

\section{REFERÊNCIAS}

ALMEIDA, J. R.; AQUINO, A. R.; ARAUJO, G. H. S.; GUENA, A. M. O.; RIOS, E. S.. Curva espécie/área para avaliação de recurso ambiental. Revista Brasileira de Pesquisa e Desenvolvimento, São Paulo, v.6, p.131-134, 2004.

BAUMOL, W. J.; OATES, W. E.. The use of standards and prices for protectionof the environment. In: BOHN, P.; KNEESE, A. V.. The economics ofenvironment. MacMillan Press, 1971
BUARQUE, C.. A desordem do processo: o fim da era dos economistas e a construção do futuro. 2 ed. São Paulo: Paz e Terra, 1990.

GUAZELLI, M. R.. O problema da poluição sob o ângulo econômico. Ambiente, São Paulo, v.6, n.1, p.60-64, 1992.

A CBPC - Companhia Brasileira de Produção Científica (CNPJ: 11.221.422/0001-03) detém os direitos materiais desta publicação. Os direitos referem-se à publicação do trabalho em qualquer parte do mundo, incluindo os direitos às renovações, expansões e disseminações da contribuição, bem como outros direitos subsidiários. Todos os trabalhos publicados eletronicamente poderão posteriormente ser publicados em coletâneas impressas sob coordenação da Cognitionis Publishing, da Companhia Brasileira de Produção Científica e seus parceiros autorizados. Os (as) autores (as) preservam os direitos autorais, mas não têm permissão para a publicação da contribuição em outro meio, impresso ou digital, em português ou em tradução. 